\title{
Caracteres anatómicos y fitoquímicos del tallo y raíz de Mammillaria uncinata (Cactaceae)
}

\section{Anatomic and phytochemical characters of the stem and root of Mammillaria uncinata (Cactaceae)}

\author{
Sofía Loza-Cornejo' (D), Xochitl Aparicio-Fernández,3 (D), Rita Judit Patakfalvil (D), Greta Hanako Rosas-Saito² (1)
}

1 Universidad de Guadalajara, Centro Universitario de los Lagos, Enrique Díaz de León Núm. 1144, Colonia Paseos de la Montaña, 47460 Lagos de Moreno, Jalisco, México.

2 Instituto de Ecología, A.C., Red de Estudios Moleculares Avanzados, Clúster Biomimic ${ }^{\circledR}$, Carretera Antigua a Coatepec 351, Congregación el Haya, 91070 Xalapa, Veracruz, México.

3 Autor para la correspondencia: xaparicio@culagos.udg.mx

Citar como:

Loza-Cornejo, S., X. Aparicio-Fernández, R. J. Patakfalvi y G. H. Rosas-Saito. 2017. Caracteres anatómicos y fitoquímicos del tallo y raíz de Mammillaria uncinata (Cactaceae). Acta Botanica Mexicana 120: 21-38. DOI: http://dx.doi.org/10.21829/ abml20.2017.1159

Recibido: 26 de septiembre de 2016. Revisado: 14 de diciembre de 2016. Aceptado: 1 de marzo de 2017.

DOI:

http://dx.doi.org/10.21829/abml20.2017.1159

\section{Resumen:}

Antecedentes y Objetivos: Los integrantes de la familia Cactaceae subsisten a través de adaptaciones anatómicas y metabólicas como la síntesis de metabolitos primarios y secundarios con funciones específicas que les permiten desarrollarse en regiones áridas y semiáridas. Mammillaria es un género perteneciente a la tribu Cacteae y la literatura con respecto a sus caracteres anatómicos y fitoquímicos es escasa. Particularmente para la especie Mammillaria uncinata los estudios con ese tipo de enfoque son ausentes, por lo que los objetivos del presente trabajo fueron describir la estructura anatómicahistoquímica y el perfil fitoquímico del tallo y la raíz de la especie con la finalidad de contribuir al conocimiento de su biología y composición química.

Métodos: El estudio se realizó con ejemplares recolectados en la región Altos Norte de Jalisco, México. Se emplearon la microtécnica convencional de inclusión en parafina y técnicas histoquímicas para la descripción de los caracteres anatómicos e histoquímicos, así como técnicas cualitativas para el estudio del perfil fitoquímico.

Resultados clave: Algunos de los caracteres anatómicos más distintivos son laticíferos que producen un látex lechoso y cristales de morfología variable en el tallo. El análisis del perfil fitoquímico reveló la presencia abundante de metabolitos secundarios en el tallo, incluyendo alcaloides, esteroles, flavonoides y saponinas, mientras que en la raíz únicamente se detectó, de manera escasa, la presencia de esteroles y saponinas.

Conclusiones: El estudio mostró la presencia, en Mammillaria uncinata, de caracteres anatómicos similares a otras especies de Cactaceae, así como la abundancia de fitoquímicos con potencial aplicación en diferentes áreas.

Palabras clave: anatomía, histoquímica, perfil fitoquímico.

\section{ABSTRACT:}

Background and Aims: Members of the Cactaceae family persist through anatomical and metabolic adaptations that allow them to develop in arid and semi-arid areas, including the synthesis of primary and secondary metabolites with specific functions. Mammillaria is a genus belonging to the Cacteae tribe and the literature on its anatomical and phytochemical characters is scarce, particularly for the species Mammillaria uncinata. Therefore, the objectives of this study were to describe the anatomicalhistochemical structure and phytochemical profile of the stem and root of Mammillaria uncinata, in order to contribute to the knowledge of biology and chemical composition of the species.

Methods: The study was conducted with specimens collected in their natural distribution area in the Altos Norte region of Jalisco, Mexico. The standard paraffin microtechnique and histochemical techniques were used for the description of the anatomical and histochemical characters, whereas qualitative techniques were applied to study the phytochemical profile.

Key results: Laticifers and crystals of variable morphology in the stem are some of the most distinctive characters. The phytochemical profile analysis revealed the presence of abundant metabolites in the stem, including alkaloids, sterols, flavonoids and saponins, whereas in the root only the presence of sterols and saponins was detected in low amounts.

Conclusions: The study showed anatomical features in Mammillaria uncinata to be similar to other Cactaceae species, as well as abundance of phytochemicals with potential application in different areas.

Key words: anatomy, histochemistry, phytochemical profile. 


\section{INTRODUCCIÓN}

La familia Cactaceae del orden Caryophyllales es un grupo de plantas suculentas representativo de las zonas áridas y semiáridas del hemisferio Oeste, excepto Rhipsalis baccifera (Sol.) Stearn, la cual se encuentra en África y Asia (Hunt, 2006).

Su división en cuatro subfamilias (Pereskioideae, Opuntioideae, Maihuenioideae y Cactoideae) ha sido sustentada por caracteres morfológicos y moleculares (Hunt, 2006; Bárcenas et al., 2011). La subfamilia Cactoideae comprende el mayor número de especies y es la más diversa en términos de hábitos de crecimiento y formas de vida; se divide en nueve tribus: Browningeae, Cacteae, Calymmantheae, Cereeae, Hylocereeae, Notocacteae, Pachycereeae, Rhipsalidae, Trichocereeae (Ortega-Baes et al., 2010; dos Santos et al., 2012; VázquezSánchez et al., 2012). En la tribu Cacteae, por ejemplo, predominan géneros como Aztekium Boed. y Mammillaria Haw., que incluyen representantes con tallos cortos, mientras que Echinocactus Link \& Otto y Ferocactus Britton \& Rose tienen integrantes con tallos globosos que miden 1 m o más de altura, así como Escobaria Britton \& Rose, Neolloydia Britton \& Rose y Thelocactus (K. Schum.) Britton \& Rose, con especies que forman tallos de entre 20 y $30 \mathrm{~cm}$ de alto (Vázquez-Sánchez et al., 2012).

Por otro lado, para sobrevivir y prosperar en ambientes hostiles, la mayoría de las cactáceas cuentan con la capacidad de sintetizar compuestos químicos variados lo que las hace productos naturales promisorios en la búsqueda de nuevas fuentes de compuestos con actividad biológica. La presencia de fitoquímicos, como esteroles, alcaloides y compuestos fenólicos (Garza-Padrón et al., 2010) que muestran actividad biológica de tipo antioxidante benéfica para el ser humano, ha sido demostrada en diversas especies, tal es el caso de Astrophytum myriostigma Lem. (Garza-Padrón et al., 2010) y diferentes especies de Opuntia Mill. (Matías et al., 2014).

Para las especies de Mammillaria, aunque es un género que incluye un gran número de especies importantes en diversos aspectos, existen pocos estudios con relación a estudios anatómicos (Janu y Raghuvanshi, 2011; Mosco, 2012; Herrera-Martínez et al., 2015), y a su perfil fitoquímico. La información existente se enfoca al estudio de los pigmentos presentes en el tallo (Wybraniec y NowakWydra, 2007; Mosco, 2012), el perfil fitoquímico y componentes nutracéuticos del fruto (Aparicio-Fernández et al., 2013), así como la inducción de metabolitos secundarios en cultivos de células en suspensión (Robles-Zepeda et al., 2009).

Por lo anterior, los objetivos del presente trabajo incluyeron la caracterización anatómica-histoquímica y el perfil fitoquímico del tallo y la raíz de Mammillaria uncinata Zuccarini \& Pfeiffer, con la finalidad de contribuir al establecimiento de las bases para el aprovechamiento de esta especie como fuente de metabolitos secundarios con actividad biológica.

\section{Materiales y Métodos}

Se llevó a cabo la recolecta de ejemplares de Mammillaria uncinata en sus áreas de distribución en municipios de Jalisco, México (Cuadro 1). Se recolectaron en promedio cinco individuos de cada localidad; dos de ellos se utilizaron para realizar el estudio morfo-ana-

Cuadro 1: Localización geográfica de localidades de recolecta de Mammillaria uncinata Zuccarini \& Pfeiffer en el estado de Jalisco, México.

\begin{tabular}{lcccc}
\hline Localidad & Latitud (N) & Longitud (O) & Altitud (m s.n.m.) & Colector/No. colecta \\
\hline Lagos de Moreno, Jal. & $21^{\circ} 31^{\prime}$ & $101^{\circ} 41^{\prime}$ & 1930 & S. Loza-Cornejo 226-230 (IBUG) \\
Ojuelos de Jalisco, Jal. & $21^{\circ} 33^{\prime}$ & $103^{\circ} 09^{\prime}$ & 2100 & S. Loza-Cornejo 231-236 (IBUG) \\
Unión de San Antonio, Jal. & $21^{\circ} 02^{\prime}$ & $101^{\circ} 27^{\prime}$ & 1920 & S. Loza-Cornejo 237-241 (IBUG) \\
Encarnación de Díaz, Jal. & $21^{\circ} 24^{\prime}$ & $102^{\circ} 25^{\prime}$ & 1851 & S. Loza-Cornejo 242-246 (IBUG) \\
\hline
\end{tabular}


tómico. Para ello, se tomaron muestras de tejido de los tubérculos y parte interna del tallo, así como muestras de la raíz. Fueron procesados dos ejemplares por localidad para el estudio de perfil fitoquímico y un ejemplar completo de cada región de muestreo se depositó en el herbario IBUG de la Universidad de Guadalajara.

\section{Anatomía e histoquímica}

Las muestras recolectadas de tallo y raíz de los individuos de M. uncinata fueron fijados con solución FAA (formaldehido-alcohol-ácido acético glacial-agua destilada, $1: 5: 0.5: 3.5)$ por $24-72$ horas y procesados para el estudio anatómico, siguiendo la microtécnica convencional de inclusión en parafina. Se realizaron cortes transversales y longitudinales de un grosor de 12-14 $\mu \mathrm{m}$ con un microtomo rotatorio (RMT-30 Radical Instruments, India), los cuales se pegaron en portaobjetos con adhesivo de Haupt, dejando secar por 12 horas. Se continuó con inmersiones en diferentes concentraciones de xileno y alcohol etílico (100\% a 50\%) para eliminar la parafina. La tinción de los tejidos se realizó con safranina $0.05 \%$ con $2 \%$ de cloruro de sodio, disueltos en agua $\mathrm{y}$ verde rápido disuelto en alcohol etílico absoluto, aceite de clavo y metilcelosolve (López-Curto et al., 1998). Posteriormente se montaron con resina sintética; una vez secas y limpias las preparaciones, se procedió a su observación con un analizador de imágenes Image Manager (Imagic Bildverarbeitung AG, 1992-2005, Berlin, Alemania), adaptado a un microscopio óptico (Leica DM-1000, Wetzlar y Mannheim, Alemania). Para el análisis con microscopía electrónica de barrido, fueron fijadas muestras del tallo en FAA, lavadas y deshidratadas en serie de alcoholes y preparadas para su observación en un microscopio electrónico (JSM-6390, Jeol, Japón) operando a $30 \mathrm{Kv}$. Para la caracterización histoquímica del tallo y de la raíz, se hicieron cortes en fresco a mano alzada, aplicando diferentes pruebas de tinción (lugol, sudán IV, Ácido Peryódico-Reactivo de Schiff (APS) y vainillina-HCl) para la identificación de almidón, lípidos, polisacáridos insolubles y taninos, respectivamente (López-Curto et al., 1998).

\section{Perfil fitoquímico}

El tallo y raíz de $M$. uncinata de las plantas limpias y sin espinas se cortaron en cubos de aproximadamente $1 \mathrm{~cm}$ de lado, los cuales posteriormente fueron deshidratados bajo condiciones ambientales $\left(14-28{ }^{\circ} \mathrm{C} ; 44-58 \%\right.$ HR) durante siete días hasta la pérdida de 85 a $95 \%$ de humedad, la cual se determinó mediante el registro de la pérdida diaria de peso. Las muestras secas se trituraron manualmente en un mortero y el polvo obtenido se sometió a extracciones secuenciales usando reflujo durante 30 minutos para la obtención de cuatro extractos de polaridad creciente (hexano, acetato de etilo, $80 \%$ etanol, agua). Los extractos se almacenaron en refrigeración $\left(4{ }^{\circ} \mathrm{C}\right)$ y se protegieron de la luz hasta su análisis. Las determinaciones se llevaron a cabo por triplicado empleando técnicas cualitativas que indican la presencia de los diferentes metabolitos mediante cambios de coloración y/o formación de precipitado, y de acuerdo a las metodologías propuestas por Domínguez (1973). La presencia de alcaloides se detectó utilizando reactivos de Dragendorff, Mayer, Warner y Hager. Los reactivos de Libermann-Burchard y Salkowski se emplearon para revelar la presencia de esteroles. La existencia de flavonoides se descubrió utilizando la prueba de Shinoda y la de las saponinas mediante la formación de espuma y con el reactivo de Rosenthaler. Se empleó $\mathrm{FeCl}_{3}$ para la detección presuntiva de taninos y soluciones acuosas de gelatina, sal y gelatina-sal, como prueba confirmatoria. La presencia de quinonas se observó utilizando $\mathrm{NaOH}$ y tolueno en solución acuosa, después de tratar los extractos

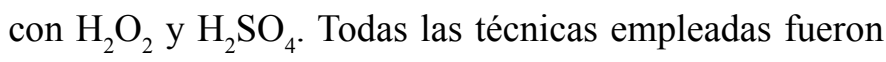
descritas por Sánchez-Herrera et al. (2011).

\section{Resultados}

\section{Anatomía e histoquímica}

La cutícula del tallo es relativamente delgada, lisa, inicia desde el nivel apical y continúa hasta las regiones cercanas a la base. La epidermis está presente en todas las regiones verdes del tallo y es uniestratificada (Fig. 1A). Las células de la epidermis son de forma cuadrada a rectangular con los bordes curvos en vista longitudinal, y de 
forma cuadrada en corte transversal; en vista superficial tienen paredes onduladas (Fig. 1C, D). Estas células no presentan algún tipo de contenido. Los estomas son paracíticos. La hipodermis es multiestratificada, colenquimatosa, compuesta por dos a cuatro estratos celulares (Fig. 1A, B). La peridermis es unidireccional, inicia en forma de parches en algunas partes del tallo y tiene un mayor desarrollo en la región media y basal. El felógeno presenta dos estratos de células con paredes delgadas, de forma rectangular; el felema está compuesto por cuatro o cinco estratos de células con pared delgada, las cuales aparecen colapsadas y alternan con estratos de células, en donde las paredes externas y radiales son gruesas y lignificadas (Fig. 1E, F). El córtex está constituido por tejido fundamental con dos tipos de células, las del clorénquima, de forma rectangular en sentido radial y cloroplastos abundantes (Fig. 2A, B) y granos de almidón (Fig. 3A, B), y las células del parénquima de reserva, las cuales son isodiamétricas, tienen paredes delgadas y también almacenan almidón. Células de mucílago y haces vasculares corticales formados por xilema y floema primarios están presentes en el tallo. En la región basal, los haces vasculares corticales ocasionalmente se presentan en grupos de hasta cuatro haces, con elementos de vaso estrechos que presentan pared secundaria helicoidal y floema con elementos de tubo criboso y células acompañantes (Fig. 2C-G). Una red de laticíferos se extiende en el córtex reservante (Fig. 4A) y se tiñe fuertemente con lugol, lo que indica la presencia de almidón. Cristales prismáticos o romboidales individuales o en conglomerados dispersos en el córtex (Fig. 4B-F), se encuentran uno o dos por célula y son relativamente grandes. En las regiones del córtex los granos de almidón son abundantes (Fig. 3G). La presencia de polisacáridos insolubles, cuerpos lipídicos y taninos oxidados en las células del córtex reservante fue también una característica distintiva del tallo (Fig. 3C-F). Los cuerpos lipídicos se concentran en la periferia de la célula, adyacentes a las paredes celulares (Fig. 3I).

El tejido vascular del xilema está constituido por una matriz de traqueidas de banda ancha, vasos escasos y células de parénquima de forma irregular (Figs. 5, 6).
Los radios son no lignificados y son principalmente secundarios. El floema se compone por elementos de tubo criboso, células acompañantes y parénquima. Granos de almidón y cristales están presentes de manera abundante en el parénquima radial (Figs. 5C, 6C-D). Los haces vasculares se presentan en número variable (Fig. 5D) y tienden a formar un cilindro sólido de xilema en la parte basal del tallo. La médula es parenquimatosa y presenta haces vasculares dispersos formados por xilema y floema primarios (Fig. 6F, G).

Se observaron raíces con crecimiento secundario. En corte transversal se observa una peridermis, parénquima, tejido vascular y una región central. La peridermis está formada por varios estratos de células colapsadas de paredes delgadas (Fig. 7A, B). En las raíces con mayor diámetro, estas células alternan con estratos de células de pared gruesa y lignificada. Las células de parénquima tienen forma isodiamétrica y se colapsan radialmente cerca de la peridermis conforme se avanza a la base de la raíz. El tejido vascular forma un anillo completo formado por el xilema secundario constituido por vasos, traqueidas de banda ancha y radios xilemáticos uniseriados, con células cuadradas a rectangulares (Fig. 7C-E).

\section{Perfil fitoquímico}

El Cuadro 2 muestra los resultados del análisis de perfil fitoquímico realizado en cuatro extractos de diferente polaridad obtenidos a partir del tallo y la raíz de $M$. uncinata. Como se puede observar los metabolitos secundarios son más abundantes en el tallo, donde se detecta la presencia de cuatro grupos, mientras que en la raíz únicamente se detectó la presencia de dos de ellos. Los alcaloides son abundantes en los extractos de mayor polaridad (etanólico y acuoso) del tallo de $M$. uncinata, mientras que no se detectó su presencia en los extractos obtenidos de la raíz. Los esteroles se presentan en cantidades bajas a moderadas en extractos de ambas partes de la planta. La presencia en cantidades bajas y moderadas de este tipo de metabolitos en los extractos obtenidos con acetato de etilo y hexano, tanto del tallo como de la raíz, sugiere una menor polaridad de dichos compuestos. Los flavonoides 

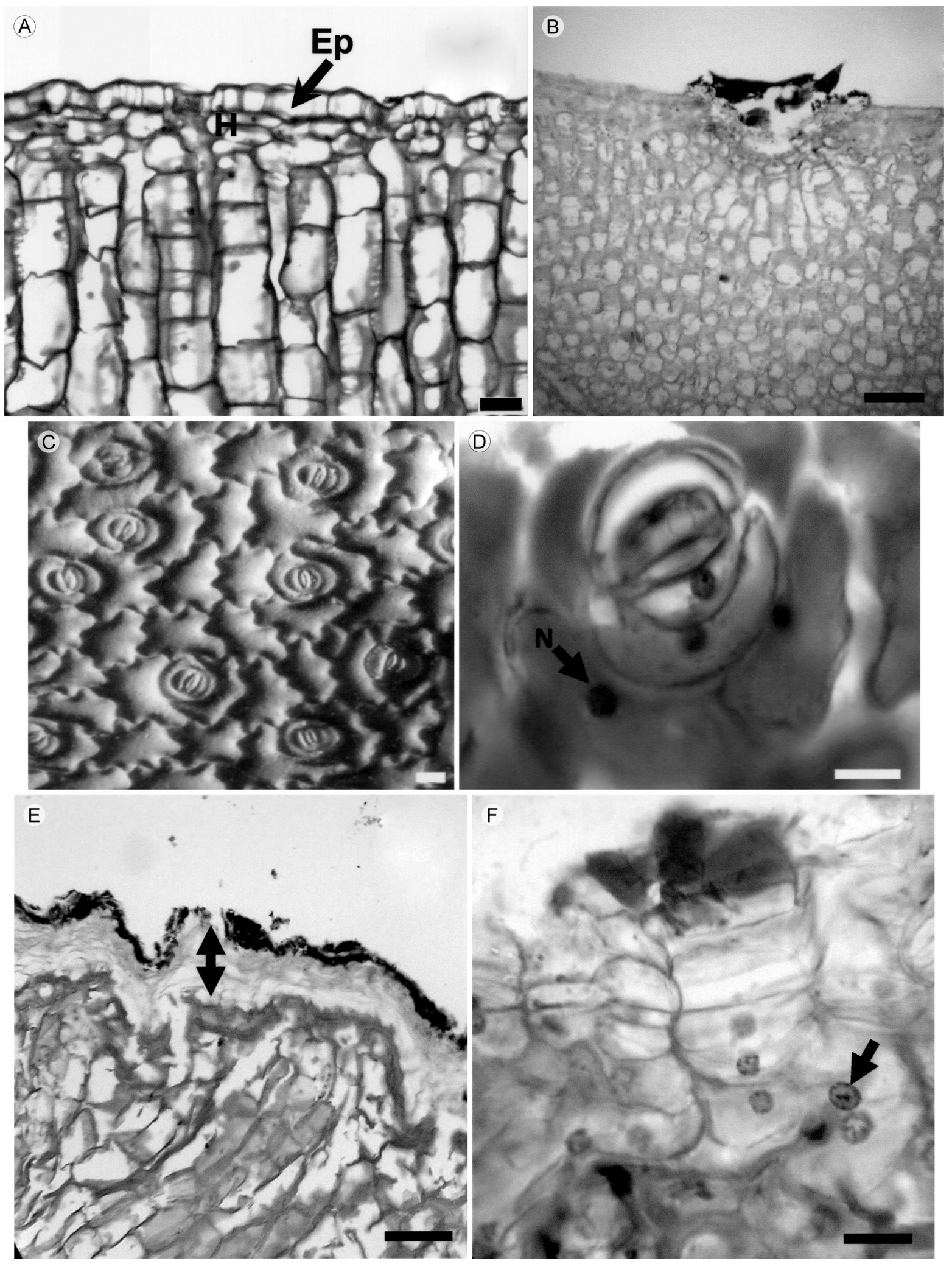

Figura 1: Cortes transversales y superficiales del tallo de Mammillaria uncinata Zuccarini \& Pfeiffer; A. epidermis uniestratificada (flecha), hipodermis y clorénquima; B. inicio de formación de peridermis; C y D. vista superficial de células epidérmicas, núcleo (flecha) y estomas; E. corte transversal del tallo mostrando células de paredes delgadas (flecha doble punta) y células de pared gruesa lignificada más externas; F. detalle de células en división en el felógeno, con núcleo conspicuo (flecha). Ep, epidermis; H, hipodermis; N, núcleo. Escala: A-C, $30 \mu$ m; D-F, $100 \mu$ m. 


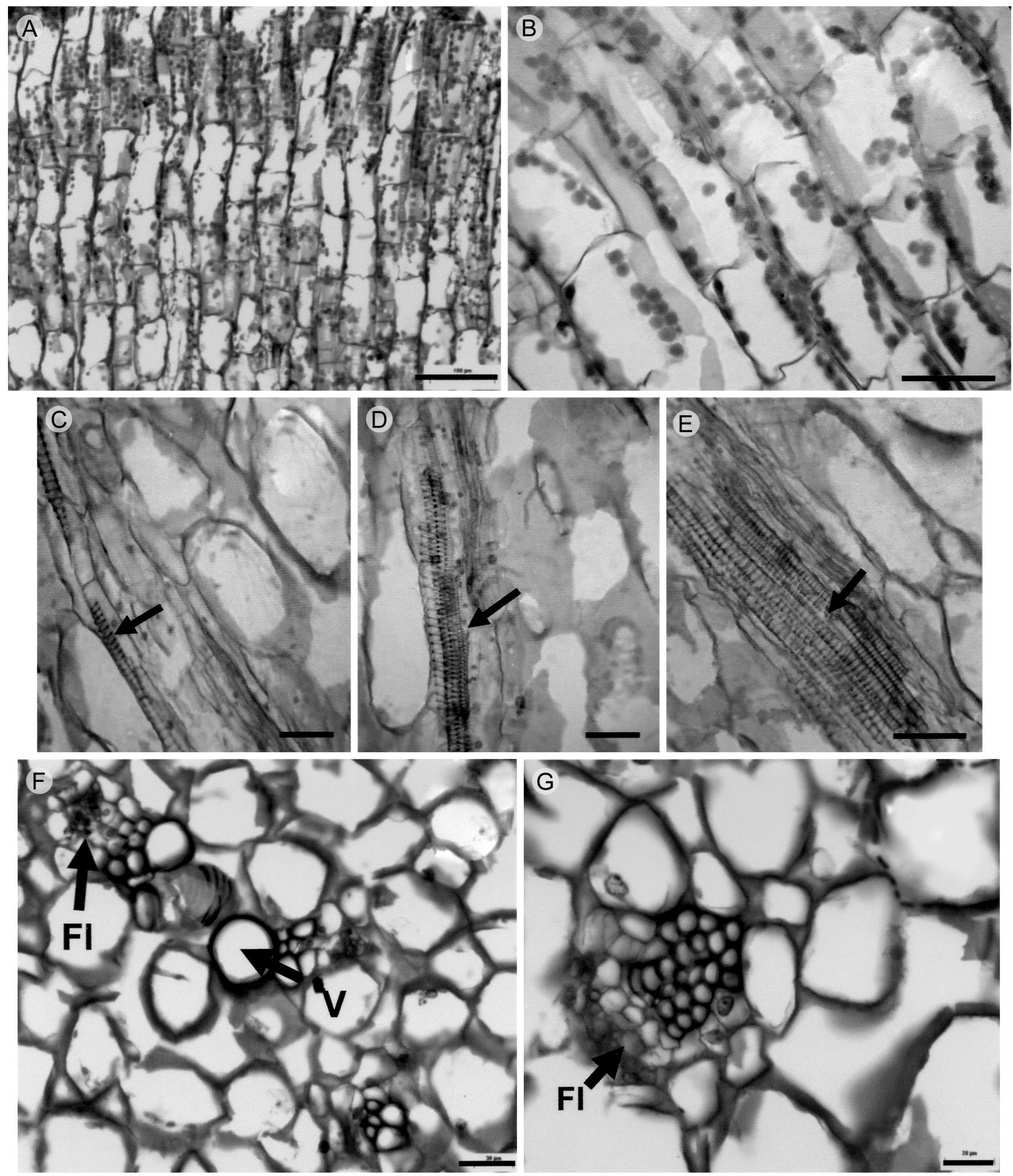

Figura 2: Cortes transversales y longitudinales del tallo de M. uncinata Zuccarini \& Pfeiffer. A. y B. córtex fotosintético con abundantes cloroplastos; haces vasculares corticales de parte apical, media y basal del tallo; C, D y E. haces vasculares corticales de parte media y basal del tallo (flechas), note la mayor acumulación de xilema en la parte basal; F y G. haces vasculares con xilema y floema (flechas). Floema (Fl), vaso (V). Escala: A, F, G, $30 \mu \mathrm{m}$; B-E, $100 \mu \mathrm{m}$. 

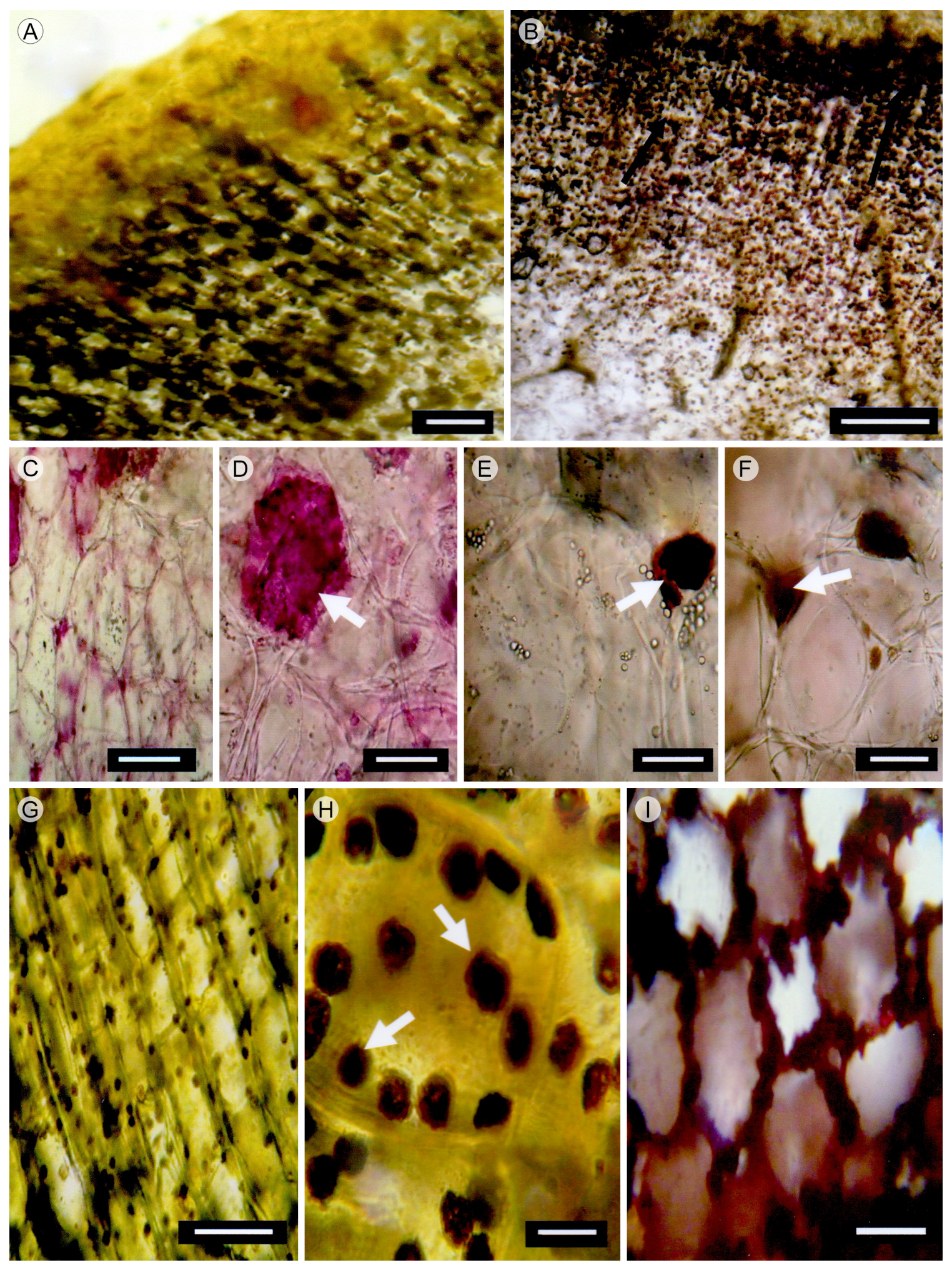

Figura 3: Cortes transversales del tallo de M. uncinata Zuccarini \& Pfeiffer. A y B. abundantes granos de almidón en el córtex fotosintético y de reserva; C y D. polisacáridos estructurales en parénquima cortical de reserva (flecha); E y F. taninos oxidados (flecha); G. detalle de granos de almidón presentes en el clorénquima; H. granos de almidón (flecha) en el parénquima de reserva; I. cuerpos lipídicos en el parénquima de reserva. Escala: A y B $300 \mu \mathrm{m}$; C-F, $20 \mu \mathrm{m} ; \mathrm{G}, 100 \mu \mathrm{m} ; \mathrm{H}, \mathrm{I}, 30 \mu \mathrm{m}$. 

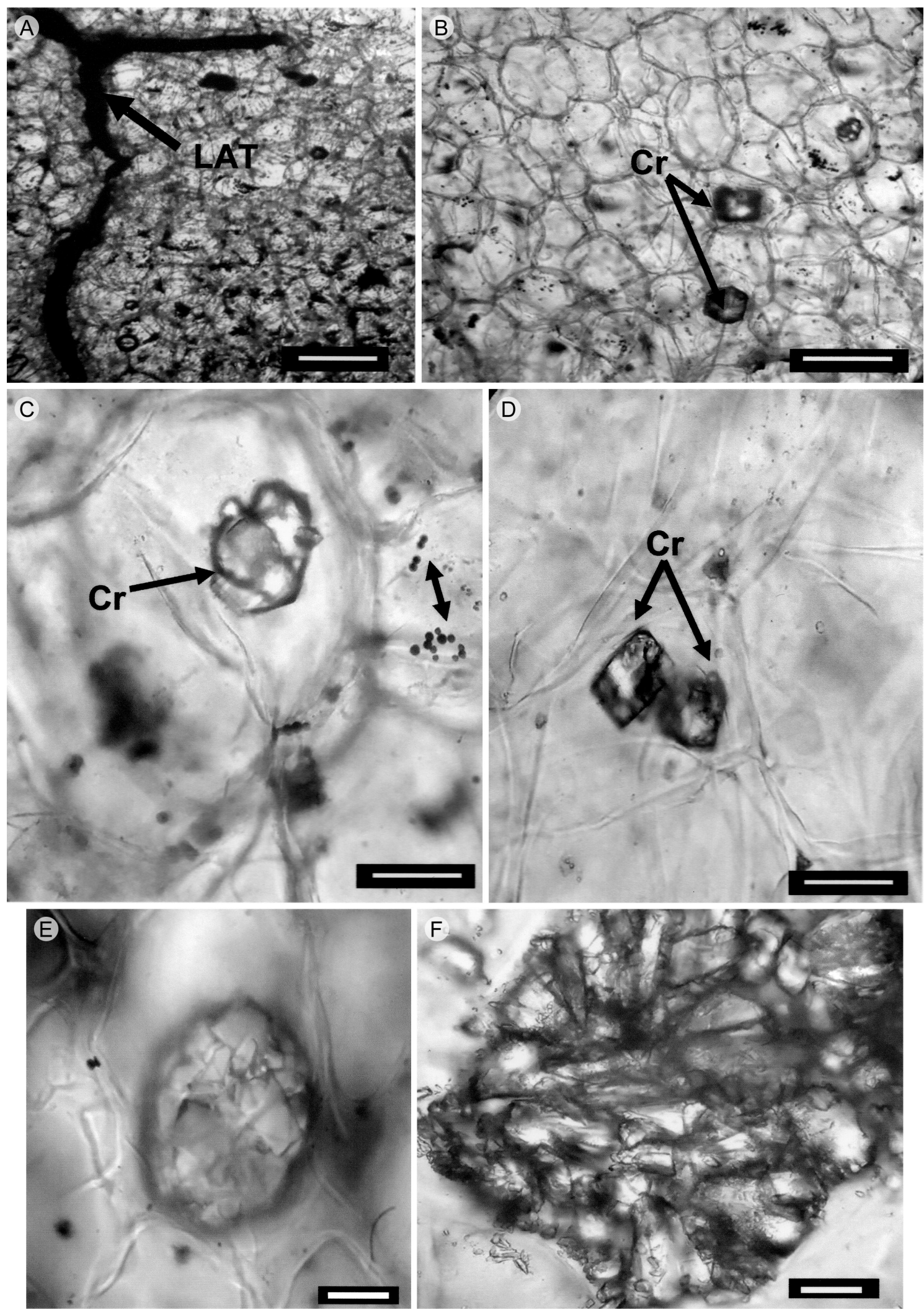

Figura 4: Cortes transversales del tallo de Mammillaria uncinata Zuccarini \& Pfeiffer. A. laticífero (flecha); B-D. granos de almidón (flecha doble punta), cristales prismáticos (flechas) en parénquima de reserva; E y F. cristales agregados. LAT, laticífero; Cr, cristales. Escala: A y B, $100 \mu \mathrm{m}$; C-E, $30 \mu \mathrm{m}$; F, $28 \mu \mathrm{m}$. 

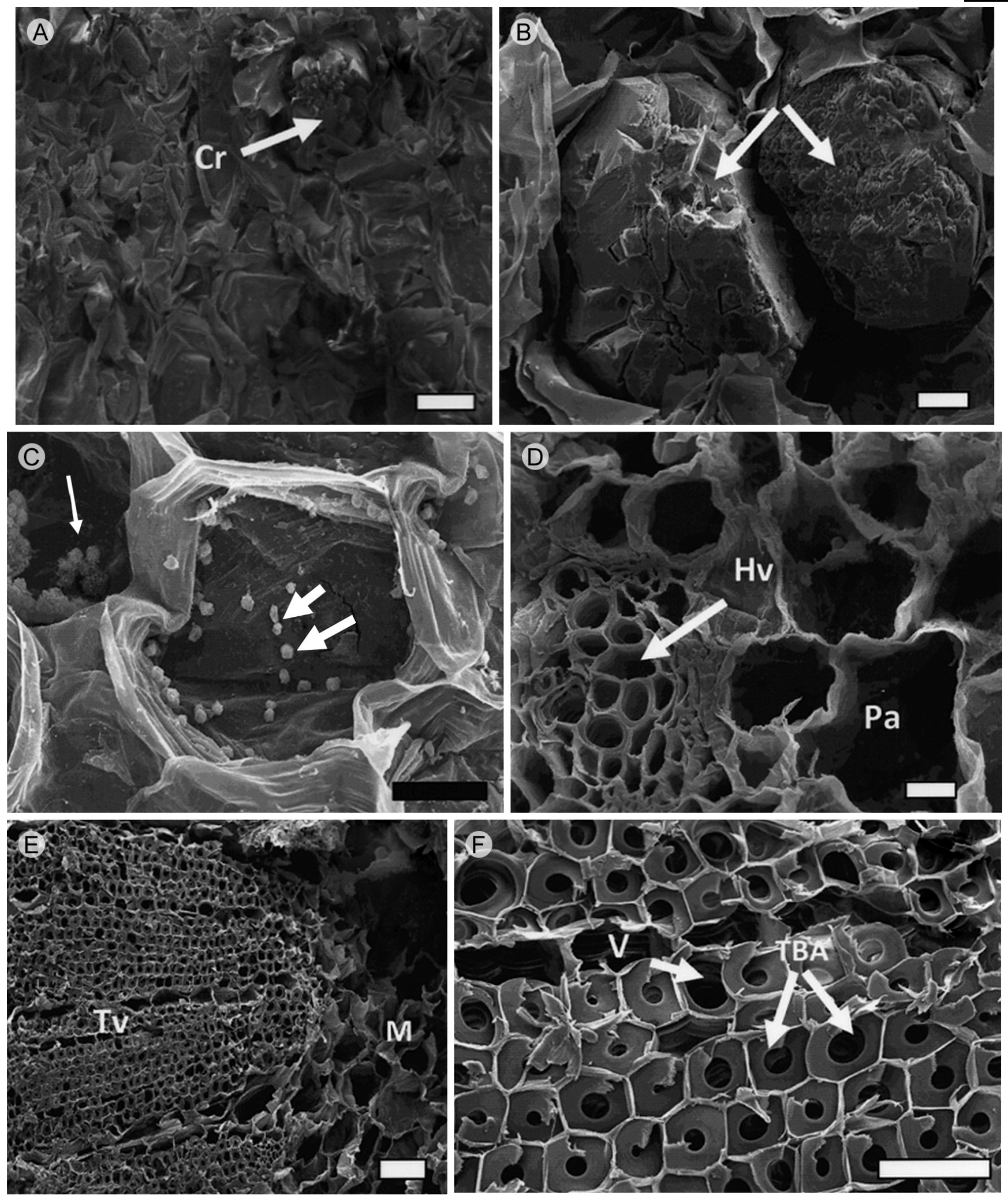

Figura 5: Cortes transversales del tallo de M. uncinata Zuccarini \& Pfeiffer observados con microscopia electrónica de barrido. A, B. cristales agregados (flechas) en parénquima cortical del tallo; C. granos de almidón en parénquima cortical (flechas); D. detalle de haz vascular cortical (flecha) y parénquima; E. tejido vascular del tallo, y médula; F. detalle de tejido vascular del tallo mostrando una matriz de traqueidas de banda ancha (flechas), y vasos escasos. Cr, cristales; Hv, haz vascular; $\mathrm{M}$, médula; Pa, parénquima; TBA, traqueidas de banda ancha; Tv, tejido vascular; V, vasos. Escala: A y E, $100 \mu \mathrm{m}$; B, $20 \mu \mathrm{m}$; C y F, $50 \mu \mathrm{m} ; \mathrm{D}, 10 \mu \mathrm{m}$. 

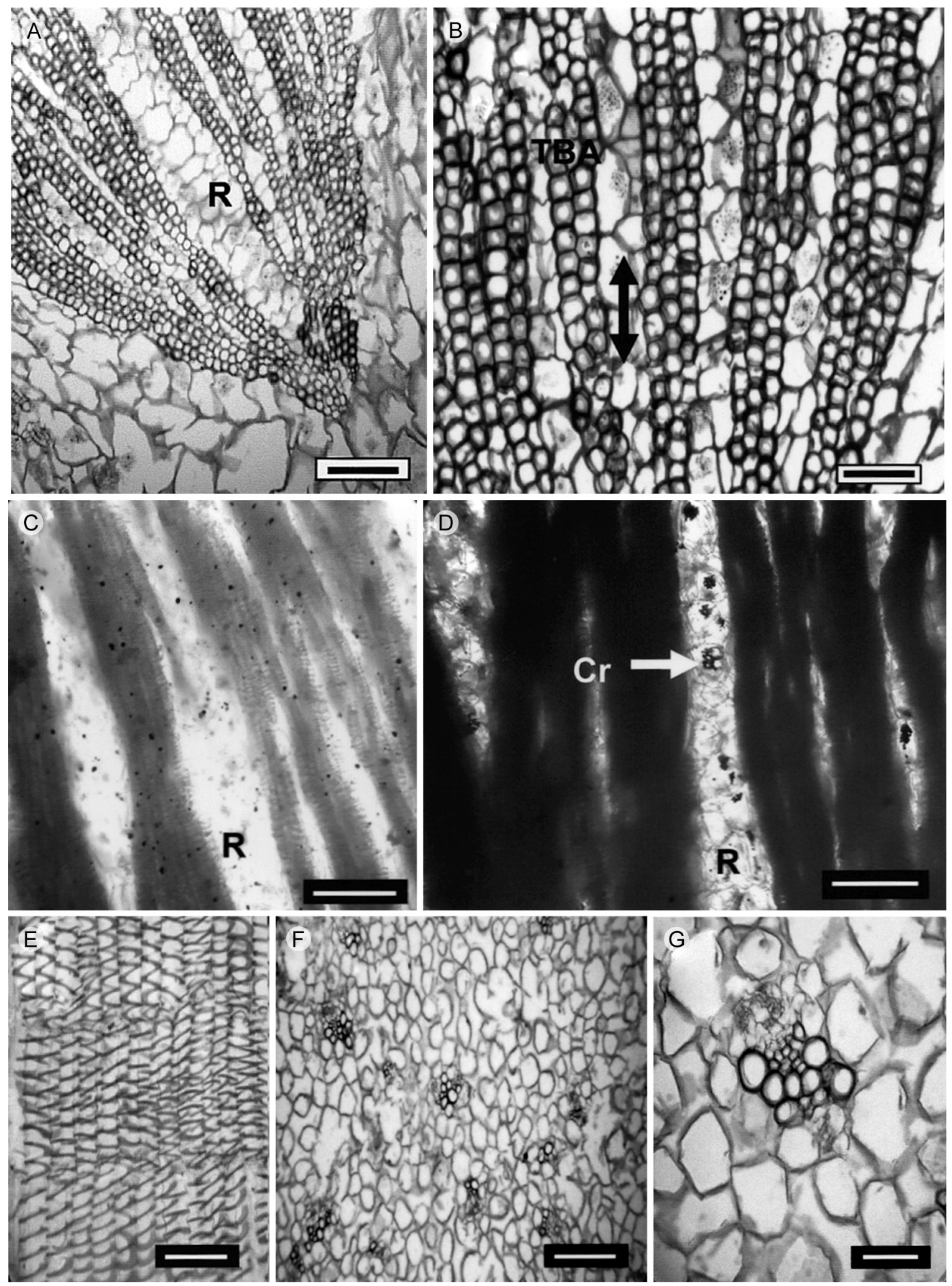

Figura 6: Cortes transversales y longitudinales del tallo de $M$. uncinata Zuccarini \& Pfeiffer. A, B. radios no lignificados (flecha doble punta) y traqueidas de banda ancha en el xilema; C y D. células de los radios con granos de almidón y cristales (flecha); E. traqueidas de banda ancha estratificadas; F. haces vasculares en la médula; G. detalle de haz vascular medular. Cr, cristales; R, radios; TBA, traqueidas de banda ancha. Escala: A y B, $100 \mu \mathrm{m} ;$ C y D. $50 \mu \mathrm{m} ; \mathrm{E}-\mathrm{G}, 150 \mu \mathrm{m}$. 

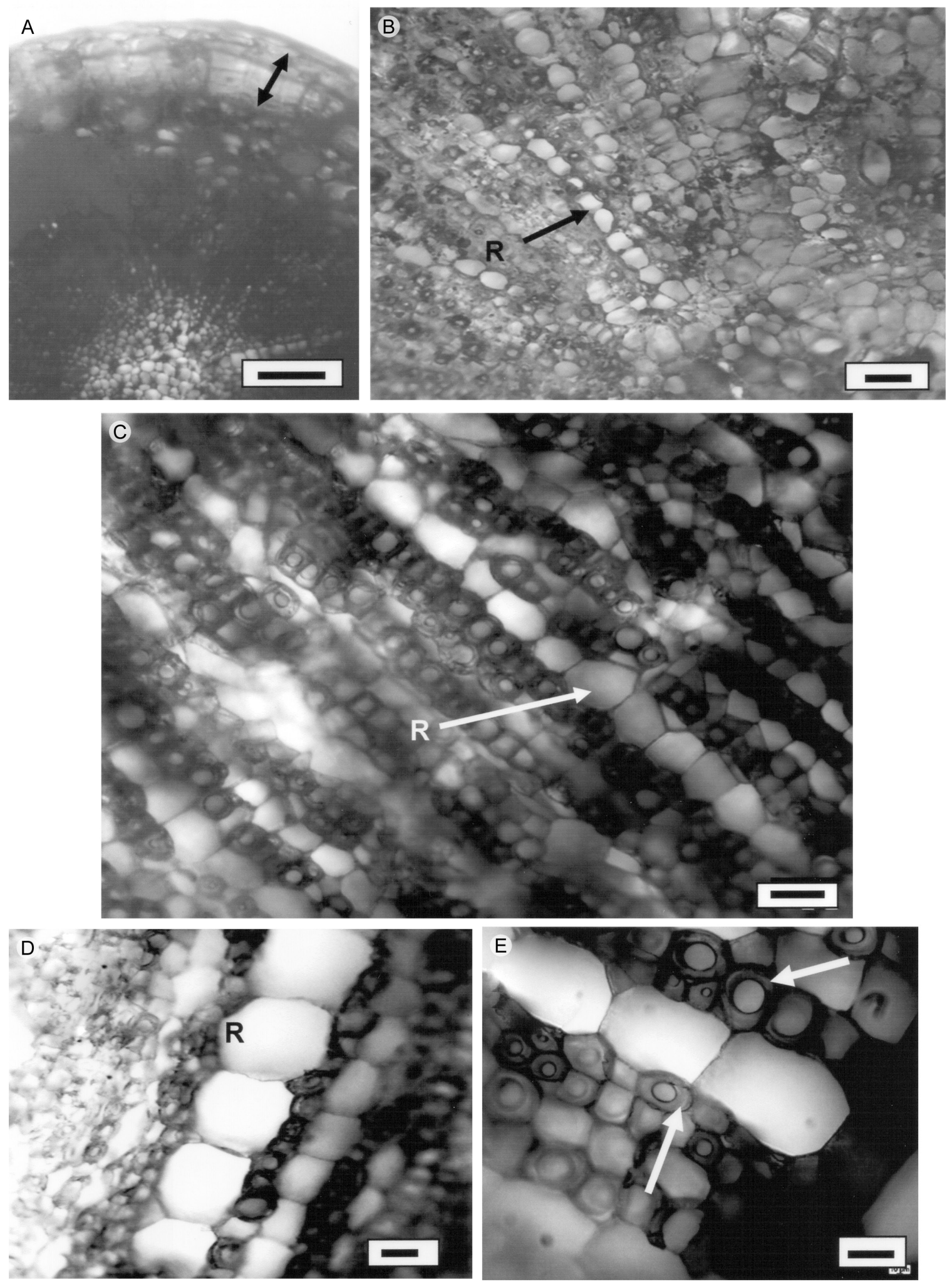

Figura 7: Cortes transversales de la raíz de Mammillaria uncinata Zuccarini \& Pfeiffer. A. desarrollo de la peridermis (flecha doble punta); B. radios uniseriados en el xilema (flecha); C-E. detalle de radios uniseriados y traqueidas de banda ancha (flechas) en el xilema. R, radios. Escala: A-C, $50 \mu \mathrm{m}$; D y E, $30 \mu \mathrm{m}$. 
Cuadro 2: Perfil fitoquímico de tallo y raíz de Mammillaria uncinata Zuccarini \& Pfeiffer analizado en cuatro extractos de diferente polaridad. Extractos: H: hexano, AE: acetato de etilo, E: $80 \%$ etanol, A: agua $(+)=$ Ensayo positivo. Contenido: + bajo, ++ moderado, +++ abundante. (-)=Ensayo negativo, ausencia.

\begin{tabular}{|c|c|c|c|c|c|c|c|c|}
\hline & \multicolumn{5}{|c|}{ Tallo } & \multicolumn{2}{|c|}{ Raíz } & \\
\hline & \multicolumn{8}{|c|}{ Extractos } \\
\hline & $\mathrm{H}$ & $\mathrm{AE}$ & $\mathrm{E}$ & $\mathrm{A}$ & $\mathrm{H}$ & $\mathrm{AE}$ & $E$ & $\mathrm{~A}$ \\
\hline Alcaloides & - & - & +++ & +++ & - & - & - & - \\
\hline Esteroles & - & ++ & + & - & ++ & + & + & - \\
\hline Flavonoides & ++ & ++ & +++ & +++ & - & - & - & - \\
\hline Saponinas & - & - & + & +++ & - & - & - & + \\
\hline
\end{tabular}

fueron abundantes en los extractos de la parte aérea de $M$. uncinata, mientras que en la raíz no se detectaron. Fue abundante la presencia de saponinas en el extracto acuoso del tallo de M. uncinata, y escasa en el extracto etanólico del tallo y en el extracto acuoso de la raíz. La presencia de taninos y quinonas no pudo detectarse con las técnicas empleadas, sugiriendo que podrían encontrarse en cantidades muy pequeñas o en forma insoluble, formando parte de estructuras celulares.

\section{Discusión}

\section{Anatomía e histoquímica}

Las características anatómicas observadas en Mammillaria uncinata son similares a las descritas para otras especies de Cactoideae (Terrazas y Arias, 2003; Salinas-Revilla y Álvarez-Moscoso, 2006; dos Santos García et al., 2012). El tallo de Mammillaria uncinata presenta una cutícula lisa y delgada que inicia a nivel apical y se conserva hasta las regiones cercanas a la base del tallo, similar a otros géneros de Cactoideae. La cutícula tiene una función importante al constituir una barrera primaria entre el cuerpo de la planta y las condiciones ambientales (Salinas-Revilla y Álvarez-Moscoso, 2006). La epidermis uniestratificada de células con pared delgada y lisa coincide con observaciones realizadas para especies de otras cactáceas (Muruaga y Guantay, 2011; dos Santos García et al., 2012; Gonçalves da Silva et al., 2013). En otras especies de Mammillaria (M. polythele Mart. y M. perbella Hildm. ex K. Schum.) la superficie de las células epidérmicas es lisa, excepto en algunas zonas donde es ligeramente rugosa (Gasson, 1981). En corte transversal, las células de la epidermis de $M$. uncinata muestran formas cuadradas o rectangulares, similar a otras cactáceas, por ejemplo, Corryocactus erectus (Backeb.) F. Ritter (Salinas-Revilla y Álvarez-Moscoso, 2006). La peridermis en el tallo se desarrolla principalmente en la región media y basal, es unidireccional y de origen epidérmico como se presenta comúnmente en Cactaceae (Terrazas y Arias, 2003; dos Santos-García et al., 2012; Gonçalves da Silva et al., 2013). Mammillaria uncinata presenta hipodermis formada por varios estratos de células de colénquima con paredes primarias. De acuerdo con Mauseth (2006), la existencia de este tipo de células en los tallos proporciona flexibilidad, permitiendo la contracción o expansión de éste, acorde con la disponibilidad de agua. Representaría, además, un mecanismo eficiente para proteger al tallo de depredadores (Soares da Silva et al., 2010; dos Santos-García et al., 2012).

El tejido cortical constituye una gran proporción del tejido suculento del tallo de M. uncinata. Su organización es típica de cactáceas ya que se diferencia en dos porciones: 1) las células exteriores del córtex que son ricas en cloroplastos y ocurren en columnas y 2) las partes centrales de tubérculos y tallo que consisten de células de parénquima isodiamétricas en un arreglo irregular. La disposición radial del clorénquima permite la difusión de $\mathrm{CO}_{2}$ a través del aumento en espacios intercelulares. Fue notoria la acumulación de granos de almidón en el clorénquima. La presencia de almidón en el córtex es de gran importancia, ya que éste es usualmente el principal carbohidrato insoluble en la mayor parte del tejido fundamental y constituye la forma más significativa de reserva de carbono en plantas en términos de su cantidad, distribución e importancia para el funcionamiento del metabolismo fotosintético (Kötting et al., 2009). En el córtex del tallo de $M$. uncinata es notoria la presencia de granos de almidón tanto en el clorénquima como en el parénquima reservante. Adicionalmente, en el parénqui- 
ma de los radios del xilema fueron también abundantes los granos de almidón. Lindeboom et al. (2004) mencionan que las condiciones ambientales temperatura, sequía y disponibilidad de nutrientes influyen en la cantidad de almidón presente. Éste podría ser el caso de M. uncinata, ya que la especie se distribuye en localidades con escasa precipitación pluvial, por lo que mantener una reserva suficiente de carbohidratos es vital para la supervivencia. Los cuerpos lipídicos o cuerpos de aceite están presentes en el parénquima cortical. Los lípidos son constituyentes esenciales de todas las células vegetales. Su contenido varía entre $5-10 \%$ del peso seco. Semillas, granos de polen, flores, raíces y tallos almacenan lípidos como material de reserva en partículas subcelulares denominadas cuerpos lipídicos, cuerpos de aceite, oleosomas o esferosomas (Ho et al., 2014). Dichas reservas constituidas principalmente por triacilglicéridos (TAGs) y proteínas oleosinas pueden ser movilizadas durante periodos de metabolismo activo (Chen et al., 1999; van der Schoot et al., 2011; Chapman et al., 2012). La presencia de lípidos o compuestos lipofílicos, como estructuras subcelulares en el tallo de $M$. uncinata, además de formar parte de las reservas de carbono en el tallo, podría representar una barrera hidrofóbica para prevenir la pérdida de agua o formar parte de una cubierta protectora contra patógenos, ataques de herbívoros y otros factores ambientales, como mencionan Rodrigues et al. (2011).

Cristales y células de mucílago están presentes en el córtex reservante del tallo de M. uncinata. Los cristales presentan una morfología similar a los de otras especies de Cactaceae (Contreras-Padilla et al., 2011). De acuerdo a Frausto-Reyes et al. (2014), la composición de dichos cristales puede ser de oxalato de calcio mono o dihidratado. La presencia de células de mucílago y cristales en el córtex son ejemplos de adaptación a hábitats xéricos de M. uncinata. Los cristales pueden reflejar la excesiva irradiación solar, mientras que la acumulación de mucílago hidrofílico facilitaría el almacenamiento de agua. La formación de cristales, además, está generalmente asociada con mecanismos de regulación de calcio en tejidos y órganos cuando los niveles de éste se incrementan en el suelo
(Hudgins et al., 2003), con la defensa contra herbívoros (Ruiz et al., 2002), así como con la regulación osmótica y detoxificación de metales (Nakata, 2003). La presencia de laticíferos es una característica distintiva del tallo de Mammillaria uncinata, similar a otras especies del mismo género (M. heyderi Muehlenpf., M. guerreronis (Bravo) Boed.) (Witler y Mauseth, 1984a, b). De acuerdo a estos autores, los laticíferos articulados presentes en Mammillaria constituyen un sistema secretor complejo que se forma por lisis de masas celulares cilíndricas que luego son rodeadas por un epitelio multicelular. El látex contenido en estos conductos contiene varias sustancias en solución y suspensión coloidal, entre las que se incluyen carbohidratos, ácidos orgánicos, sales, esteroles, grasas y mucílagos. Son comunes también los terpenoides (cis-1, 4 poliisoprenos) y gomas, aunque otras sustancias pueden estar presentes, tales como glicósidos cardíacos, alcaloides, azúcares, proteínas y taninos (Konno, 2011), algunos de los cuales se detectaron en el perfil fitoquímico. Los laticíferos contienen una gama amplia de metabolitos secundarios; sin embargo, ninguno es movilizado o participa en el metabolismo celular. De acuerdo a Konno (2011) y Roshchina y Roshchina (2012), los laticíferos sirven como sistemas para "secuestrar" metabolitos secundarios tóxicos, los cuales pueden tener una función de protección contra herbívoros; este podría ser el caso de Mammillaria uncinata. Los taninos son los metabolitos secundarios más abundantes producidos por las plantas y contribuyen por su toxicidad a la defensa contra insectos herbívoros al inducir en éstos un estrés oxidativo (Barbehenn y Constabe, 2011; Salminen y Karonen, 2011). La presencia de taninos en el tallo de M. uncinata fue escasa, solamente algunas células del córtex reservante presentaron este contenido, motivo por el cual no fueron detectados en el análisis del perfil fitoquímico.

El xilema secundario está constituido por una matriz de traqueidas de banda ancha, vasos escasos y células de parénquima. Los haces vasculares se presentan en número variable y tienden a formar un cilindro sólido de xilema secundario con radios no lignificados. El floema se compone por elementos de tubo criboso, células acompa- 
ñantes y parénquima como se presenta también en otras cactáceas (Terrazas y Arias, 2003).

La raíz de Mammillaria uncinata está constituida por peridermis, parénquima, xilema y floema secundarios, además de las células de parénquima en la región central. Las células de parénquima subyacentes a la peridermis con disposición radial que ocupan una mayor proporción de tejido en la raíz. La peridermis se caracteriza por presentar varios estratos de células esclerificadas, semejante a otras especies de Cactaceae (Terrazas y Arias, 2003).

\section{Perfil fitoquímico}

Los resultados del estudio fitoquímico realizados en $M$. uncinata complementan el estudio histoquímico, mostrando un panorama más amplio sobre la composición química de la especie. Los diferentes tipos de metabolitos secundarios detectados en el análisis del perfil fitoquímico de $M$. uncinata son sintetizados en la planta para ayudar a su protección y supervivencia (Konno, 2011; Roshchina y Roshchina, 2012); sin embargo, todos ellos pueden presentar algún tipo de actividad biológica en el organismo humano. Por lo tanto, $M$. uncinata podría considerarse como una especie potencial como fuente de fitoquímicos.

La abundante presencia de alcaloides en los extractos polares obtenidos del tallo sugiere que estos compuestos se encuentran en forma de sales (Arango, 2002). La presencia de alcaloides ha sido reportada en el tallo de otras especies de cactáceas globosas; por ejemplo, Sánchez-Herrera et al. (2011) registraron mayor abundancia de alcaloides en el tallo de Coryphantha clavata (Scheidw.) Backeb., que en su raíz. Un comportamiento similar encontramos en la presente investigación, ya que solo se detecta la presencia de alcaloides en el tallo, mientras que en la raíz están ausentes. A la fecha no existen evidencias sobre las propiedades de los alcaloides presentes en M. uncinata, probablemente por el hecho de ser una especie no utilizada en la medicina tradicional, por lo que resulta de interés el continuar con el estudio en cuanto a la concentración y el tipo de alcaloides, ya que éstos podrían presentar algún tipo de actividad biológica.
Los esteroles, también llamados triterpenos, forman parte de estructuras importantes en las membranas de células vegetales, y cumplen diversas funciones que van desde protección (ceras) hasta regulación del crecimiento como son las fitoalexinas (Céspedes et al., 2005). Diferentes especies vegetales sintetizan esteroles, aunque en una variedad de formas y concentraciones, dependiendo de cada planta y de las condiciones ambientales (Piironen et al., 2000). De acuerdo a Domínguez (1973), los esteroles pueden encontrarse en diferentes formas químicas (libres, como ésteres, o glicósidos). En el presente trabajo se detectó la presencia de esteroles, presumiblemente en dos formas químicas diferentes, ya que los detectados en el tallo presentaron mayor polaridad que los de la raíz. La presencia de esteroles en especies de cactáceas ha sido estudiada y se ha mencionado que algunos de ellos presentan efectos biológicos. Por ejemplo, Jiang et al. (2006), concluyeron sobre el descubrimiento de dos nuevos esteroles en tallos de Opuntia dillenii (Ker Gawl.) Haw. Por otro lado, Sri Nurestri et al. (2008) mostraron resultados sobre la actividad citotóxica de extractos obtenidos de hojas de Pereskia bleo (Kunth) DC., los cuales son ricos en esteroles. La cactácea columnar Myrtillocactus geometrizans (Mart. ex Pfeiff.) Console presenta compuestos de tipo esteroles tanto en la parte aérea, como en la raíz y éstos tienen un efecto insecticida (Céspedes et al., 2005). El estudio de dichas moléculas fue retomado por Salazar et al. (2011) quienes demostraron que dichas sustancias tienen, además, actividad antiinflamatoria y citotóxica.

Los flavonoides son un grupo de compuestos fenólicos de amplia distribución en plantas, incluyendo diferentes especies de Cactaceae. Su comprobada capacidad como antioxidantes y otras formas de actividad biológica los ha hecho blanco de diferentes estudios (Alimia et al., 2010; Angulo-Bejarano et al., 2014; Gutiérrez-Grijalva et al., 2016). Los extractos obtenidos del tallo de M. uncinata muestran contenidos importantes de estos compuestos, mientras que en la raíz no se evidenció su existencia. Los resultados sugieren la presencia de diferentes tipos de flavonoides con distintas características de solubilidad, así como la importancia de la luz para su síntesis en las plantas, 
ya que únicamente se detectaron en el tallo. La presencia de flavonoides en los frutos de M. uncinata (Aparicio-Fernández et al., 2013), así como en especies de Opuntia (Matías et al., 2014; Hahm et al., 2015) ha sido establecida con anterioridad incluyendo su capacidad antioxidante.

Las saponinas son glucósidos solubles en agua con capacidad para disminuir la tensión superficial y formar espuma al agitar sus soluciones. Al hidrolizar las saponinas se forman carbohidratos y una aglicona llamada sapogenina que puede presentar estructuras de tipo esteroidal, triterpénico o tetracíclico, entre otras (Domínguez, 1973). La presencia de saponinas se detecta en los extractos más polares del tallo y raíz de $M$. uncinata sugiriendo que se encuentran en forma glicosilada. En investigaciones previas del equipo de trabajo (Aparicio-Fernández et al., 2013) se encontró la presencia de saponinas en los frutos de la misma cactácea. La presencia de estos compuestos ha sido descrita en otras especies de cactáceas (Okazaki et al., 2011; Kakuta et al., 2012), y algunas de ellas han demostrado actividad biológica, destacando la actividad antialérgica de tipo I.

La presencia de taninos no se detecta mediante las técnicas cualitativas empleadas en el análisis del perfil fitoquímico. Sin embargo, sí fueron detectados mediante pruebas histoquímicas, loque sugiere que estos componentes se encuentran en pequeñas cantidades firmemente unidos a las paredes celulares y de forma insoluble. Por su importante efecto biológico como antioxidantes fuertes, los taninos podrían considerarse parte de la fibra antioxidante y a M. uncinata una fuente de ésta (Barbehenn y Constabe, 2011; Salminen y Karonen, 2011).

\section{CONCLUSIONES}

Este estudio muestra la presencia de caracteres anatómicos en Mammillaria uncinata similares a otras especies de Cactaceae, destacando la presencia de cristales de morfología variable en el tallo, así como laticíferos. Dada la diversidad de compuestos fitoquímicos (alcaloides, esteroles, flavonoides y saponinas) detectados en el tallo y raíz de $M$. uncinata, se considera de trascendencia su descubrimiento, así como de relevancia el continuar con su estudio en la búsqueda de moléculas con actividad biológica que puedan ser aplicados en beneficio de la salud humana. Lo anterior sugiere la potencialidad de $M$. uncinata como fuente de fitoquímicos con actividad biológica.

\section{CONTRIBUCIONES DE LOS AUTORES}

SLC y XAF concibieron, diseñaron el estudio y realizaron los análisis. RJP llevó a cabo parte de los experimentos y revisó los borradores del documento. GHR participó en la toma de imágenes de microscopía electrónica de barrido. Todos los autores contribuyeron a la discusión, revisión y aprobación del manuscrito final.

\section{FINANCIAMIENTO}

El estudio no tuvo financiamiento por parte de ningún proyecto, se realizó con recursos de la Universidad de Guadalajara.

\section{AgradeCIMIENTOS}

Agradecemos a Adriana Campos Medina, por el apoyo brindado en la preparación de las muestras y en etapas iniciales de la investigación. Un especial agradecimiento al Laboratorio de Psicobiología del Centro Universitario de los Lagos, Universidad de Guadalajara, por facilitarnos el uso del microscopio óptico y procesador de imágenes. Agradecemos también a los revisores anónimos de Acta Botanica Mexicana por sus valiosos comentarios para mejorar el presente documento.

\section{LITERATURA CITADA}

Alimia, H., N. Hfaiedha, Z. Bouonia, M. Hfaiedha, M. Saklyb, L. Zourguia, y K. Ben Rhoumab. 2010. Antioxidant and antiulcerogenic activities of Opuntia ficus indica f. inermis root extract in rats. Phytomedicine 17(14): 1120-1126. DOI: http://dx.doi.org/10.1016/j.phymed.2010.05.001

Angulo-Bejarano, P. I., O. Martínez-Cruz y O. Paredes-López. 2014. Phytochemical content, nutraceutical potential and biotechnological applications of an ancient Mexican plant: nopal (Opuntia ficus-indica). Current Nutrition \& Food Science 10: 196-217. DOI: http://dx.doi.org/10.217 $4 / 157340131003140828121015$ 
Aparicio-Fernández, X., S. Loza-Cornejo, M. G. TorresBernal y N. J. Velázquez-Placencia. 2013. Chemical and morphological characterization of Mammillaria uncinata (Cactaceae) fruits. Journal of the Professional Association for Cactus Development 15: 32-41.

Arango, A. G. J. 2002. Alcaloides y Compuestos Nitrogenados. Facultad de Química Farmacéutica. Universidad de Antioquia. Medellín, Colombia. 88 pp.

Barbehenn, R. V. y C. P. Constabe. 2011. Tannins in plantherbivore interaction. Phytochemistry 72(13): 1551-1565. DOI: http://dx.doi.org/10.1016/j.phytochem.2011.01.040

Bárcenas, R. T., C. Yesson y J. A. Hawkins. 2011. Molecular systematics of the Cactaceae. Cladistics 27(5): 470-489. DOI: http://dx.doi.org/10.1111/j.1096-0031.2011.00350.x

Céspedes, C. L., J. R. Salazar, M. Martínez y E. Aranda. 2005. Insect growth regulatory effects of some extracts and sterols from Myrtillocactus geometrizans (Cactaceae) against Spodoptera frugiperda and Tenebrio molitor. Phytochemistry 66(20): 2481-2493. DOI: http://dx.doi. org/10.1016/j.phytochem.2005.07.010

Chapman, K. D., J. M. Dyer y R. T. Mullen. 2012. Biogenesis and functions of lipid droplets in plants: Thematic Review Series: Lipid Droplet Synthesis and Metabolism: from Yeast to Man. Journal of Lipid Research 53: 215-226. DOI: http://dx.doi.org/10.1194/jlr.R021436

Chen, J. C. F., C. C. Y. Tsai y J. T. C. Tzen. 1999. Cloning and secondary structure analysis of caleosin, a unique calcium binding protein in oil bodies of plant seeds. Plant Cell Physiology 40(10): 1079-1086.

Contreras-Padilla, M. E., E. Pérez-Torrero, M. I. HernándezUrbiola, G. Hernández-Quevedo, A. del Real, E. M. Rivera-Muñoz y M. E. Rodríguez-García. 2011. Evaluation of oxalates and calcium in nopal pads (Opuntia ficus-indica var. redonda) at different maturity stages. Journal of Food Composition and Analysis 24(1): 38-43. DOI: http://dx.doi.org/10.1016/j.jfca.2010.03.028

Domínguez, X. A. 1973. Métodos de Investigación Fitoquímica. Limusa. México, D.F., México. 281 pp.

dos Santos García, J., E. Scremin-Dias y P. Soffiatti. 2012. Stem and root anatomy of two species of Echinopsis (Trichocereeae: Cactaceae). Revista Mexicana de
Biodiversidad 83(4): 1036-1044. DOI: http://dx.doi. org/10.7550/rmb.28124

Frausto-Reyes, C., S. Loza-Cornejo, T. Terrazas, M. L. MirandaBeltrán, X. Aparicio-Fernández, M. B. López-Macías, S. E. Morales-Martínez y M. Ortiz-Morales. 2014. Raman spectroscopy study of calcium oxalate extracted from cacti stems. Applied Spectroscopy 68(11): 1260-1265. DOI: http://dx.doi.org/10.1366/14-07485

Garza-Padrón, R. A., M. J. Verde-Star, M. E. Morales-Rubio, A. Oranday-Cárdenas, C. Rivas-Morales, M. A. NúñezGonzález y M. P. Barrón-González. 2010. Actividad amebicida, antioxidante y perfil fitoquímico de extractos metanólicos de Astrophytum myriostigma obtenidos de cultivo de callo y del cactus silvestre. Polibotánica 30: 111-121.

Gasson, P. 1981. Epidermal anatomy of some North American globular cacti. The Cactus and Succulent Journal of Great Britain 43:101-108.

Gonçalves da Silva, C. H. G., A. Calvente, A. Soller y L. T. Maranho. 2013. Anatomía de Rhipsalis subgênero Erythrorhipsalis A. Berger (Rhipsalideae, Cactaceae). Iheringia, Série Botanica 68(2): 249-259.

Gutiérrez-Grijalva, E. P., D. L. Ambriz-Pére, N. LeyvaLópez, R. I. Castillo-López y J. Basilio-Heredia. 2016. Review: dietary phenolic compounds, health benefits and bioaccessibility. Archivos Latinoamericanos de Nutrición 66(2): 87-100.

Hahm, S. W., J. Park, S. Y. Oh, C. W. Lee, K. Y. Park, H. Kim y Y. S. Son. 2015. Anticancer properties of extracts from Opuntia humifusa against human cervical carcinoma cells. Journal of Medicinal Food 18(1): 31-44. DOI: http://dx.doi.org/10.1089/jmf.2013.3096

Herrera-Martínez, V., L. Ríos-Hernández, C. Garcidueñas-Piña, A. Lara-Ibarra, A. Adabache-Ortiz, R. E. Soria-Guerra, E. Pérez-Molphe-Balch y J. F. Morales-Domínguez. 2015. Effect of culture conditions on stomatal density and stomatal index in four cactus species. Haseltonia 20: 4350. DOI: http://dx.doi.org/10.2985/026.020.0108

Ho, L. S., A. Nair, H. M. Yusof, H. Kulanveerasingan y M. S. Jangi. 2014. Morphometry of lipid bodies in embryo, kernel and mesocarp of oil palm: Its relationship to yield. 
American Journal of Plant Sciences 5: 1163-1173. DOI: http://dx.doi.org/10.4236/ajps.2014.59129

Hudgins, J. W., T. Kreklin y V. R. Franceschi. 2003. Distribution of calcium oxalate crystals in the secondary phloem of conifers: a constitutive defense mechanism? New Phytologist 159(3): 677-690. DOI: http://dx.doi. org/10.1046/j.1469-8137.2003.00839.x

Hunt, D. 2006. The New Cactus Lexicon. DH Books. Milborne Port, UK. 373 pp.

Janu, V. y R. K. Raghuvanshi. 2011. Microscopic studies on epidermal cells and stomatal behavior of some globular cacti (Mammillaria spp.). Insight Botany 1(1): 1-4. DOI: http://dx.doi.org/10.5567/BOTANY-IK.2011.1.4

Jiang, J., Y. Li, Z. Chen, Z. Min y F. Lou. 2006. Two novel C295beta-sterols from the stems of Opuntia dillenii. Steroids 71(13-14): 1073-1077. DOI: http://dx.doi.org/10.1016/j. steroids.2006.09.005

Kakuta, K., M. Baba, S. Ito, K. Kinoshita, K. Koyama y K. Takahashi. 2012. New triterpenoid saponins from cacti and anti-type I allergy activity of saponins from cactus. Bioorganic and Medicinal Chemistry Letters 22(14): 4793-4800. DOI: http://dx.doi.org/10.1016/j. bmcl.2012.05.058

Konno, K. 2011. Plant latex and other exudates as plant defense systems: roles of various defense chemicals and proteins contained therein. Phytochemistry 72(13): 1510-1530. DOI: http://dx.doi.org/10.1016/j.phytochem.2011.02.016

Kötting, O., D. Santelia, C. Edner, S. Eicke, T. Marthaler, M. S. Gentry, S. Comparot-Moss, J. Chen, A. M. Smith, M. Steup y G. Ritte. 2009. Starch-excess is a laforin-like phoshoglucan phosphatase required for starch degradation in Arabidopsis thaliana. The Plant Cell 21(1): 334-346. DOI: http://dx.doi.org/10.1105/tpc.108.064360

Lindeboom, N., P. R. Chang y R. T. Tyler. 2004. Analytical, biochemical and physicochemical aspects of starch granule size, with emphasis on small granule starches: a review. Starch/Stärke 56(3-4): 89-99. DOI: http://dx.doi. org/10.1002/star.200300218

López-Curto, M. L., J. Márquez-Guzmán y G. MurguíaSánchez. 1998. Técnicas para el estudio del desarrollo en angiospermas. Libro de Laboratorio. Facultad de
Ciencias, Universidad Nacional Autónoma de México. México, D.F., México. 116 pp.

Matías, A., S. L. Nunes, J. Poejo, E. Mecha, A. T. Serra, P. J. Madeira, M. R. Bronze y C. M. Duarte. 2014. Antioxidant and anti-inflammatory activity of a flavonoid-rich concentrate recovered from Opuntia ficus-indica juice. Food and Function 5(12): 3269-3280. DOI: http://dx.doi. org/10.1039/c4fo00071d

Mauseth, J. D. 2006. Structure-function relationships in highly modified shoots of Cactaceae. Annals of Botany 98(5): 901-926. DOI: http://dx.doi.org/10.1093/aob/mcl133

Mosco, A. 2012. Tissue localization of betacyanins in cactus stems. Revista Mexicana de Biodiversidad 83(2): 413420.

Muruaga, N. B. y M. E. Guantay. 2011. Aspectos epidérmicos en especies de Rebutia (Cactaceae-Cactoideae) de la Argentina. Boletín de la Sociedad Latinoamericana y del Caribe de Cactáceas y Otras Suculentas 8(3): 19-22.

Nakata, P. A. 2003. Advances in our understanding of calcium oxalate crystal formation and function in plants. Plant Science 164(6): 901-909. DOI: http://dx.doi.org/10.1016/ S0168-9452(03)00120-1

Okazaki, S., K. Kinoshita, S. Ito, K. Koyama, H. Yuasa y K. Takahashi. 2011. Triterpenoid saponins from Echinopsis macrogona (Cactaceae). Phytochemistry 72(1): 136-146. DOI: http://dx.doi.org/10.1016/j.phytochem.2010.10.004

Ortega-Baes, P., S. Sühring, J. Sajama, E. Sotola, M. AlonsoPedano, S. Bravo y H. Godínez-Álvarez. 2010. Diversity and conservation in the cactus family. In: Ramawat, $\mathrm{K}$. G. (ed.). Desert Plants, Biology and Biotechnology. Springer-Verlag. Berlin, Germany. Pp. 157-173. DOI: http://dx.doi.org/10.1007/978-3-642-02550-1_8

Piironen, V., D. G. Lindsay, T. A. Miettinen, J. Toivo y A. M. Lampi. 2000. Plant sterols: biosynthesis, biological function and their importance to human nutrition. Journal of the Science of Food and Agriculture 80(7): 939-966. DOI: http://dx.doi.org/10.1002/(SICI)10970010(20000515)80:7<939::AID-JSFA644>3.0.CO;2-C

Robles-Zepeda, R. E., M. Jiménez-Estrada, A. NavarroOcaña, I. Saad-Villegas, I. Brunner y E. Ruiz-Bustos. 2009. Secondary metabolites induction in Mammillaria 
huitzilopochtli (Cactaceae) and evaluation of the fungicidal activity. African Journal of Biotechnology 8(16): 3874-3878. DOI: http://dx.doi.org/10.5897/ AJB09.243

Rodrigues, T. M., S. de Pádua Texeira y S. Rodrigues M. 2011. The oleresin secretory systems in seedlings and adult plants of Copaiba (Copaifera langsdorffii Desf., Leguminosae-Caesalpinioideae). Flora-Morphology, Distribution, Functional Ecology of Plants 26(6): 585-594. DOI: https://dx.doi.org/10.1016/j.flora.2010.10.002

Roshchina, V. V. y V. D. Roshchina. 2012. The Excretory Function of Higher Plants. Springer Science Bussiness Media. Londres, UK. 314 pp. DOI: https://dx.doi. org/10.1007/978-3-642-78130-8

Ruiz, N., D. Ward y D. Saltz. 2002. Calcium oxalate crystals in leaves of Pancreatum sickenbergeri: constitutive or induced defense? Functional Ecology 16: 99-105.

Salminen, J. P. y M. Karonen. 2011. Chemical ecology of tannins and other phenolics: we need a change in approach. Functional Ecology 25(2): 325-338. DOI: http://dx.doi. org/10.1111/j.1365-2435.2010.01826.x

Salazar, J. R., M. Martínez-Vázquez, C. L. Céspedes, T. Ramírez-Apan, A. Nieto-Camacho, J. Rodríguez-Silverio y F. Flores-Murrieta. 2011. Anti-inflammatory and cytotoxic activities of chichipegenin, peniocerol, and macdougallin isolated from Myrtillocactus geometrizans (Mart. ex Pfeiff.) Con. Zeitschrift Naturforschung C 66(12): 24-30. DOI: http://dx.doi.org/10.1515/znc-2011-1-204

Salinas Revilla, N. y E. Álvarez Moscoso. 2006. Anatomía y morfología de Corryocactus erectus (Backeberg) Ritter (Cactaceae). Zonas áridas 10: 102-114.

Sánchez-Herrera, R., M. A. Sotelo-Olague, X. AparicioFernández y S. Loza-Cornejo. 2011. Coryphantha spp. proximate composition and phytochemical profile. Journal of the Professional Association for Cactus Development 13: 36-47.
Soares da Silva, M. G., J. C. B. Dubeux, L. C. D. S. Cortes, D. L. Mota, L. L. S. da Silva, M. V. F. dos Santos y D. C. dos Santos. 2010. Anatomy of different forage cacti with contrasting insect resistance. Journal of Arid Environments 74(6): 718-722. DOI: http://dx.doi.org/ 10.1016/j.jaridenv.2009.11.003

Sri Nurestri, A. B., A. W. Norhanom, Y. Hashim, K. S. Sim, S. L. Hong, G. S. Lee y N. S. A. R. Syarifah. 2008. Cytotoxic activity of Pereskia bleo (Cactaceae) against selected human cell lines. International Journal of Cancer Research 4(1): 20-27. DOI: http://dx.doi.org/10.3923/ ijcr.2008.20.27

Terrazas, T. y S. Arias. 2003. Comparative stem anatomy in the subfamily Cactoideae. The Botanical Review 68: 444473.

van der Schoot, C., L. K. Paul, S. B. Paul y P. L. Rinne. 2011. Plant lipid bodies and cell-cell signaling. A new role for an old organelle? Plant Signaling \& Behavior 6(11): 17321738. DOI: http://dx.doi.org/10.4161/psb.6.11.17639

Vázquez-Sánchez, M., T. Terrazas y S. Arias. 2012. El hábito y la forma de crecimiento en la tribu Cacteae (Cactaceae, Cactoideae). Botanical Sciences 90(2): 97-108. DOI: http://dx.doi.org/10.17129/botsci.477

Witler, G. H. y J. D. Mauseth. 1984a. Schizogeny and ultrastructure of developing latex ducts in Mammillaria heyderi (Cactaceae). American Journal of Botany 71(1): 100-110.

Witler, G. H. y J. D. Mauseth. 1984b. Schizogeny and ultrastructure of developing latex ducts in Mammillaria guerreronis (Cactaceae). American Journal of Botany 71(8): 1128-1138. DOI: http://dx.doi.org/10.2307/2443389

Wybraniec, S. y B. Nowak-Wydra. 2007. Mammillarinin: a new malonylated betacyanin from fruits of Mammillaria. Journal of Agricultural and Food Chemistry 55(20): 81388143. DOI: http://dx.doi.org/10.1021/jf071095s 